\title{
Sindicalização e Negociação Coletiva na Administração Pública: Estudo Comparado das Realidades Jurídicas Brasileira e Argentina
}

Maria Cecília Mendes Borges'

"El funcionariado público muchas veces presionado por múltiples y variadas responsabilidades valora y necesita de la labor reflexiva." Jorge Luis Maiorano

\section{Introdução}

A sindicalização e a negociação coletiva na Administração Pública são institutos regulamentados tanto pelo direito brasileiro quanto pelo direito argentino, sendo fonte de infindáveis controvérsias e debates, que passam pela natureza jurídica do vínculo que une o servidor ao Estado, pelos princípios regentes da Administração Pública, pela interdisciplinaridade entre o direito administrativo e o direito do trabalho, devendo-se levar em conta as finalidades de ditos institutos, chegando-se às tendências internacionais $\mathrm{e}$ aos direitos fundamentais.

Todavia, a despeito de toda a discussão jurídica - doutrinária e jurisprudencial -, certo é que, no mundo dos fatos, a realidade é outra. A todo instante, como é notório, a imprensa noticia inúmeros conflitos eclodidos nos diversos setores da Administração Pública, incluídas as atividades essenciais, com prejuízos aos usuários, ao Estado e aos próprios funcionários, devendo-se assinalar também a corrente prática de violência contra os sindicalistas.

Acompanham-se comumente nos noticiários brasileiros movimentos sindicais de servidores públicos, reivindicando desde condições melhores de trabalho, passando por aspectos sociais até políticas trabalhistas mais humanizadas.

Pós-graduada em Direito Público pela Universidade Gama Filho e mestre em Direito Administrativo pela Universidade Federal de Minas Gerais. 
Na Argentina, a situação não difere muito de nossa realidade, até mesmo pela proximidade cultural e histórica que une ambas as naçōes. Como registram os jornais, sempre são convocadas pelos sindicatos argentinos paralisações, com acatamento, em geral, de $80 \%$ a $90 \%$ dos trabalhadores, atingindo os serviços públicos (JIMÉNEZ, 2001), resultando muitas vezes em violência contra os servidores públicos (TAMAYO, 2000).

Por outro lado, a contribuição argentina, paralelamente à brasileira, tem sido das mais significativas, nas Américas, para o progresso do direito administrativo, como entende Cretella Júnior (CRETELLA JÚNIOR, 1966, p. 260), que qualifica aquele país como centro de séria elaboração científica do direito administrativo (CRETELLA JÚNIOR, 1966, p. 243).

Justifica-se, assim, um estudo comparado do direito nos países mencionados.

A presença dos dois países no Mercado Comum do Cone Sul (Mercosul), como líderes naturais, é outro argumento a justificar o estudo conjunto de seus ordenamentos jurídicos, a despeito de, como disse Rivero (RIVERO, 1995, p. 156), ao tratar do sistema do direito administrativo latino-americano, a homogeneidade estar longe de ser absoluta, que também não é o que se quer.

Como já disse Roberto Dromi (DROMI, 1991, p. 117), a decisão de reformar e transformar é irreversível.

\section{Sindicalização e negociação coletiva na administração pública}

Os livros de História noticiam que desde os tempos remotos, com destaque para a Idade Média, o homem tenta se agrupar de acordo com suas ocupaçōes e em defesa de seus interesses comuns. Quando os interesses são profissionais, podem se formar associações em defesa dos interesses das categorias, tanto de empregados quanto de empregadores, conhecidas simplesmente como associações profissionais, sendo uma de suas manifestaçōes o sindicato que, segundo Délio Maranhão e Luiz Inácio Carvalho (MARANHĀO; CARV'ALHO, 1993, p. 307), é um dos símbolos da democracia.

A palavra grêmio é utilizada pela doutrina jurídica argentina como sinônimo ao que se conhece por sindicato no Brasil.

Aspecto básico da liberdade sindical (OIT, 1993, p. 18), o direito de negociação coletiva pode ser equiparado a uma conversa, de boa-fé, entre empregador e representante dos empregados, relativamente às condiçōes de emprego. A doutrina registra, a despeito da amplitude de conteúdo das negociações, que numerosos convênios têm se restringido às meras remunerações.

Uma das vias nas quais se pode desdobrar a negociação coletiva é a convenção coletiva, que é intersindical, circunscrevendo seu âmbito nas respectivas representações das categorias. Pode-se ainda firmar um acordo coletivo, este pactuado 
entre o sindicato de trabalhadores e uma ou mais empresas, sendo seu âmbito restrito ao destas últimas. Assim, as convenções coletivas são o gênero do qual acordos coletivos são espécie, podendo-se conceituar acordo coletivo como uma convenção coletiva de âmbito normativo reduzido.

No direito argentino, Hugo Mansueti (MANSUETI, 2000, p. 14) define convênio coletivo de trabalho como um contrato que, homologado, resulta obrigatório, completando Miguel Sardegna (SARDEGNA, 1995, p. 73) que produz efeitos erga omnes no ramo de atividade e âmbito territorial da representação, haja ou não a filiação ao grêmio, em virtude da solidariedade de interesses, com efeito de normativa jurídica geral, não se podendo prejudicar as condições e direitos já contemplados.

Discute-se acerca da natureza jurídica da convenção coletiva, basicamente em torno de três teorias, as contratualistas ou civilistas, as regulamentares ou publicistas (seria como que uma convençāo-lei, devido ao estabelecimento de modelos que servirão de normas, não se destinando à criação de situaçōes subjetivas) e as mistas (que entendem ser contratual em sua formação, devido ao acordo de vontades, e assemelhada à norma jurídica pelo seu conteúdo e efeitos, com alcance não somente aos signatários), sendo esta última a corrente dominante.

Em uma relação de trabalho, seu conteúdo é formado por cláusulas normativas, o que também ocorre no setor público. Entretanto, no que tange às sentenças normativas, não se as têm admitido nas relaçōes funcionais do setor público, pois, como define Paulo Emílio Ribeiro de Vilhena (VILHENA, 1978, p. 213), trata-se de uma das fontes de direito que, editada pelos Tribunais do Trabalho, tem por fim o estabelecimento de normas e condições de trabalho e que irradia efeitos jurídicos gerais, abstratos, para o futuro, com campos de incidência objetivo-subjetiva limitada, entretanto, às categorias profissionais e econômicas que se tenham envolvido no processo de dissídio coletivo.

Como fundamento do direito coletivo, não se pode deixar de garantir a liberdade de coalizão, traduzindo a possibilidade jurídica da união em defesa de interesses comuns.

No presente trabalho, em que se pretende estudar os institutos supraconceituados na Administração Pública, é necessário que se estabeleça o que se entenderá por esta expressão e pelo servidor público a ela vinculado.

Adotar-se-á o entendimento da administrativista Maria Sylvia Zanella Di Pietro (DI PIETRO, 1999, p. 53), para quem a ideia de administração pública estritamente considerada compreende, em sentido subjetivo, as pessoas jurídicas, órgãos e agentes públicos que exercem a função administrativa, e, em sentido objetivo, a atividade administrativa exercida por esses entes. Sintetizando este entendimento, o não menos brilhante administrativista Hely Lopes diz que a Administração Pública em sentido material é o conjunto das funções necessárias aos serviços públicos em geral (MEIRELLES, 1999, p. 59), tendo como seus princípios básicos, em especial, legalidade, moralidade, impessoalidade e eficiência. 
Quanto ao termo servidor público, neste trabalho será considerado o conceito de pessoa física que presta serviços à Administração, mediante remuneração, possuindo vínculo empregatício ou relação profissional. Ou, segundo Celso Antônio Bandeira de Mello (MELLO, 1999, p. 179), servidor público é a designação genérica que abrange todos aqueles que mantêm vínculos de trabalho profissional com as entidades governamentais.

Isso porque, na doutrina argentina, diferentemente da brasileira, há grande confusão e quase nenhum consenso quanto à real diferenciaçāo entre funcionário e empregado públicos. Rafael Bielsa entende que o funcionário público expressa a vontade estatal, e por isso seu vínculo seria externo, ao passo que o vínculo do empregado público seria interno com a Administração. Rodolfo Bullrich, por sua vez, não vê razão para a distinção, aduzindo terem ambos as mesmas características. Da mesma forma, a natureza jurídica da função pública e do emprego público é controvertida na doutrina argentina, alguns entendendo ser contrato de direito público, outros ato bilateral, havendo ainda quem entenda ser ato unilateral ou ainda contrato de direito privado, restando esta última, contudo, ultrapassada.

No Brasil, não há grandes controvérsias a respeito da diferenciação entre servidores estatutários, sob o regime administrativo, de um lado, e empregados públicos, de outro, contratados sob o regime da legislação trabalhista, como esclarece Di Pietro (DI PIETRO, 1999, p. 355), entendendo quase toda a doutrina jurídica no sentido desta diferenciação.

Assim, adotando-se no presente trabalho o termo geral servidor público, como acima caracterizado, defender-se-á a aplicação a ambos - empregados e funcionários públicos, indistintamente, de alguns institutos de direito coletivo, especificamente neste estudo, a possibilidade de sindicalização e de negociação coletiva. Adotaremos, assim, o conceito elaborado pelo Convênio 151 da Organizaçāo Internacional do Trabalho, como todas as pessoas empregadas pela Administração Pública, admitindo que haja limitações quanto à aplicação a empregados de alto nível, com poder decisório, cargos diretivos ou cujas obrigaçōes sejam de natureza altamente confidencial, bem como às forças armadas e à polícia.

É necessário ressaltar que, divergências doutrinárias à parte quanto à inclusão ou não dos servidores militares na classificação supramencionada, no presente trabalho eles não estão incluídos no que se chamou por servidores públicos.

Assim é que, especificamente na Administraçāo Pública, argumenta-se que, quanto aos servidores submetidos ao regime público - seja qual for o nomem iuris que se lhes dê a doutrina - não haveria possibilidade de qualquer modificação das normas vigentes por meio de contrato, ainda que com a concordância da Administração e do funcionário, porque se trata de normas de ordem pública, não derrogáveis pelas partes (DI PIETRO, 1999, p. 356).

Não se pode deixar de consignar que ainda há os que entendem que, devido ao fato de o trabalhador estatal ser o próprio Estado, e de ter o dever de servi-lo, não se pode enxergar o mesmo com os mesmos olhos com os quais se enxerga 
o trabalhador privado, como citado em algumas passagens de sua obra por Antônio Augusto Anastásia (ANASTÁSIA, 1990); logo, por isso, o servidor público não teria direito à negociação coletiva e à sindicalização.

Neste trabalho, com vistas especialmente ao direito argentino e ao direito brasileiro, procura-se demonstrar nossa posição contrária a essa tese, que pensamos estar ultrapassada. Não adianta invocar uma Administração Pública ultrapassada, fruto de um paradigma distante, para impor a seus agentes a vontade emanada de forma unilateral.

Especificamente quanto à negociação coletiva dos servidores públicos, há quem defenda ser incompatível com os princípios da legalidade e do orçamento público. Equivocam-se os que assim entendem, pois, de acordo com os conceitos vistos, está se confundindo negociação coletiva com convenf̧ão ou acordo coletivo. Como bem observa Carlos Henrique Leite, ao citar Arion Sayão Romita (LEITE, 2002), a negociação coletiva é um procedimento preparatório, sendo somente em momento posterior a possivel celebração dos referidos contratos-leis, exemplificando que, no caso brasileiro, nos termos do $\$ 2^{\circ}$ do artigo 114 da Constituição Federal de 1988, ao ajuizamento de dissídio coletivo perante a Justiça do Trabalho.

Se, por um lado, o reconhecimento das convençōes e acordos coletivos ao servidor público - especialmente o regido pelo regime administrativo, pode se chocar com os princípios da legalidade e do orçamento público, devido ao processo legislativo que implique aumento de despesas dos servidores públicos, essa circunstância não impede que esses mesmos servidores, por meio de seu sindicato, estabeleçam negociação coletiva com o representante do ente da Administração Pública.

Seguindo-se o raciocínio de Carlos Leite (LEITE, 2002), no esteio de Arion Sayão Romita, a negociação coletiva dá margem a debates de variados assuntos, não se limitando, de forma alguma, a aspectos salariais, podendo se discutir, entre outros, acerca da saúde e segurança do trabalho, alteraçōes tecnológicas, flexibilização do trabalho, não-discriminação, participação nas decisões e vários outros assuntos relacionados à qualidade de vida no trabalho.

Assim, negociar coletivamente não significa que as partes sejam obrigadas a celebrar convenção ou acordo coletivo, pelo que se encontra equivocado o entendimento de que os servidores públicos não poderiam se sindicalizar e participar em negociaçōes coletivas.

É perfeitamente possível, no âmbito da Administração Pública, em consonância com os princípios do Estado Democrático de Direito, que a negociação coletiva seja operacionalizada como um "protocolo de intençōes", em uma mesa-redonda da qual participem o representante da entidade pública e o sindicato dos servidores, sendo esta uma inteligente sugestão do mencionado autor.

Esse protocolo de intenções poderá ser encaminhado ao responsável pela iniciativa do processo legislativo, como (sugestão de) um projeto de lei, contendo as cláusulas acordadas entre as partes. 
Daí em diante, se encaminhado ao Poder Legislativo, o projeto seguiria seu trâmite regular, com amplos debates, inerentes ao processo legislativo.

Dessa forma, embasado materialmente na negociação coletiva, formalmente resultar em uma lei, e não em uma convenção ou acordo coletivo, satisfazendo-se assim os princípios da Administração Pública e do Estado Democrático de Direito, especialmente o princípio da legalidade.

Defendemos, ainda, que em caso de a negociação coletiva restar infrutífera, estaria legitimado o direito de os servidores públicos declararem greve. Este, todavia, é assunto para uma outra monografia.

\section{Sindicalização e negociação coletiva dos servidores públicos no direito brasileiro}

Sindicalização e negociação coletiva são institutos muito próximos, podendose até mesmo afirmar da quase impossibilidade de se estudar um sem menção ao outro. Tanto é assim que a Constituição Federal de 1988 (CF/88) determina, no inciso VI de seu artigo $8^{\circ}$, a obrigatoriedade da participação dos sindicatos nas negociações coletivas de trabalho.

Com o novo texto constitucional, houve alteração na organização sindical no Brasil, conferindo-se autonomia às entidades sindicais, nos termos de seu artigo 8ㅇ, o que, todavia, para Délio Maranhão e Luiz Inácio Carvalho (MARANHĀO; CARVALHO, 1993, p. 312), ainda não se trata de liberdade sindical, devido à existência de sindicato único para cada categoria e às contribuiçōes sindicais.

A CF/88 dedica o Capítulo VII de seu Título III - Da Organização do Estado, à Administração Pública, com uma Seção específica aos servidores públicos, cujo regime, em virtude da exclusão da norma constitucional do regime jurídico único através da Emenda Constitucional no 19/1998 (EC no 19/98), ficará a cargo de cada esfera do governo, com liberdade para adotar "regimes jurídicos diversificados, seja o estatutário, seja o contratual" (DI PIETRO, 1999, p. 361). Todavia, essa posição não é pacífica na doutrina, havendo quem defenda que persiste somente o regime estatutário.

Discussões doutrinárias, nesse tocante, à parte, interessa saber, quanto aos servidores regidos pelo regime administrativo, sobre a aplicabilidade dos institutos da sindicalização e negociação coletiva.

Quanto aos servidores chamados empregados públicos na doutrina brasileira, não há dúvida quanto à possibilidade de sindicalização e negociação coletiva, tendo em vista se lhes aplicar o regime trabalhista, sendo-lhes reconhecidos os acordos e convençōes coletivos de trabalho, nos termos do inciso XXVI da $\mathrm{CF} / 88$, e a sindicalização, para viabilizar a negociação coletiva, conforme artigo $8^{\circ}$ da Carta Magna. 
No que tange à sindicalização, é garantido ao servidor púbico o direito à livre associação sindical, nos termos do inciso VI do artigo 37 da CF/88, não se restringindo as ações dos sindicatos aos associados, podendo alcançar demais membros da categoria. Especificamente quanto aos servidores federais, a Lei Federal $\mathrm{n}^{9}$ 8.112, de 11 de dezembro de 1990, assegura no caput do artigo 240 o direito à livre associação sindical. Referidas normas incorporaram, assim, as recomendações da Organização Internacional do Trabalho, sobre a institucionalização de meios voltados à composição dos conflitos de natureza coletiva oriundos da relação de trabalho entre o Poder Público e seus servidores, especialmente a Convenção nº 151.

Quanto à possibilidade de negociação coletiva, para defendermos a tese proposta neste trabalho, estudaremos a situação dos servidores públicos federais regidos pela mencionada Lei $\mathrm{n}^{\circ} 8.112 / 90$, portanto, estatutários.

Inicialmente, não se pode deixar de mencionar que o artigo $39, \mathbb{3} 3^{\circ}$ (primitivo $\$ 2^{\circ}$, transformado em terceiro pela $E C n^{\circ} 19 / 98$ ), da CF/88, estendeu aos servidores estatutários alguns direitos assegurados aos trabalhadores sob vínculo trabalhista, entre os quais o de compensação de horários e redução de jornada, mediante acordo ou convenção coletiva de trabalho, previsto no inciso XIII do artigo $7^{\circ}$ da $\mathrm{CF} / 88$. Penso já aí se encontrar uma semente para a ampliação da negociação coletiva aos servidores sob o vínculo administrativo.

No que toca à Lei no 8.112/90, em sua redaçāo original, o artigo 240 assegurava ao servidor público, no caput do artigo, o direito à livre associação sindical e, na alínea $d$, o direito "dela decorrente" de negociação coletiva.

Submetida a julgamento pelo Supremo Tribunal Federal (STF), na Ação Direta de Inconstitucionalidade $n^{\circ} 492-1$ - DF, a alínea $d$ do artigo 240 da Lei $n^{\circ}$ $8.112 / 90$ foi declarada inconstitucional pelo Tribunal, por maioria de votos (LEX, 1993, p. 90).

Entre outros argumentos, o relator da ação, o Ministro Carlos Velloso, elencou a natureza de regime estatutário, cujos direitos e deveres são definidos unilateralmente pelo Estado-legislador. Argumentou ainda que a negociação coletiva tem por escopo básico a alteração da remuneração, que, para os servidores públicos, decorre de lei, havendo ainda a revisão geral, que se faz na mesma data para os servidores, dizendo que, malograda a negociação, segue-se o dissídio coletivo, no qual os Tribunais do Trabalho estabelecem as condições de trabalho para as partes. Fundamenta-se ainda na impossibilidade de a Administração Pública transigir no que diz respeito à matéria reservada à lei.

Do lado oposto, o Ministro Marco Aurélio, em seu voto, cita a evolução do direito estrangeiro na matéria, e, especificamente quanto ao direito à negociação coletiva, questiona qual a valia se todos puderem negociar, menos o "majestático" Estado. Entende ser paradoxal a possibilidade de sindicalização com o reconhecimento da proibição de dialogar, aventando a possibilidade de se firmarem acordos coletivos. 
Como vimos anteriormente, os argumentos aduzidos pelo Relator na ADI supramencionada nāo são capazes de abalar os argumentos favoráveis à negociação coletiva, pois, como visto, não se trata de extirpar as normas regentes do regime administrativo ou estatutário, mas de possibilitar aos servidores e Administração Pública o diálogo, como brilhantemente esposado pelo Ministro Marco Aurélio. Quanto a ser a alteração da remuneração uma das principais finalidades da negociação, já foi visto que a negociação coletiva é muito mais ampla. Por fim, quanto ao dissídio coletivo, não se há que fazer vinculação entre este e a negociação coletiva, sendo assunto para uma outra monografia sua possibilidade ou não quanto aos servidores públicos... Assim, entende-se equivocado o entendimento do Supremo Tribunal Federal, na pessoa do Relator da ADI no 492-1/DF, principalmente ao confundir negociação coletiva com convenção ou acordo coletivo.

Posteriormente, a Lei $\mathrm{n}^{\circ}$ 9.527, de 10 de dezembro de 1997, revogou referida norma. Todavia, isso não significa que tenha se aniquilado a possibilidade de o servidor federal negociar coletivamente. O direito possui muitas outras facetas, sendo a legislativa somente uma delas.

Defende-se por fim que, malograda a negociação, estaria legitimado o direito de greve dos servidores públicos. Ora, a negociação coletiva pode afastar o impasse, o conflito seguido de greve.

Toda a discussāo jurídica deve levar em consideração a sociedade que regula. Como muito bem consignado pelo Ministro Sepúlveda Pertence, na ADI no 492-1/DF, a negociação coletiva será um fato, uma inevitabilidade política, que gerará consequências jurídicas. Assim, no mundo dos fatos a realidade é outra, e sem o canal de negociação coletiva dos servidores públicos brasileiros, não há como negar que os conflitos e as medidas de ação direta, principalmente a danosa greve, tendem a ser essencialmente políticos, restando como única alternativa, quando deveriam ser a última alternativa.

Defende-se, pois, a possibilidade fática e jurídica de sindicalização e negociação coletiva na Administração Pública brasileira.

\section{Sindicalização e negociação coletiva dos servidores públicos no direito argentino}

Sindicalização e negociação coletiva, como visto, são institutos intimamente relacionados, não sendo exagero afirmar da inexistência de um sem o outro. Tanto é assim que a Constituição da Nação (cuja última grande alteração se deu em 1994), em seu artigo 14 bis, agregado pela Convenção reformadora de 1957, garante aos grêmios o direito de firmar negociações coletivas.

A despeito de haver registros de juristas que interpretam o dispositivo amplamente (MANCINI, 1998, p. 444), trata-se de vozes dissidentes, possuindo legitimidade para negociar coletivamente as associaçōes mais representativas, ou seja, 
com personalidade gremial, salvo se as não houver, quando então as associações sindicais sem personalidade gremial poderão negociar, nos termos dos artigos 23 e 31 da Lei no 23.551/88. Segundo Guillermo López (LÓPEZ, 1995, p. 1765), trata-se do sistema de personalidade gremial no regime de pluralidade sindical.

Os trabalhadores também gozam de direitos sindicais, sendo assegurada organização sindical livre e democrática, sem necessidade de autorização prévia, a filiação às associaçōes já constituídas ou desvinculação das mesmas, com o pleno desenvolvimento de atividades sindicais, nos termos do artigo $4^{\circ}$ da Lei retromencionada, como consagrou o constituinte argentino no artigo 14 bis.

Defende-se ser o direito à liberdade sindical um direito fundamental, reconhecido pelos países que se dizem democráticos, como é o caso da Argentina, nos termos da Constituição Nacional, especialmente os artigos 36, 38 e 75.

A doutrina argentina é tradicionalista, entendendo Rafael Bielsa (BIELSA, 1964, p. 247) e Jose Canasi (CANASI, 1981, p. 682) que os funcionários e os empregados da Administraçāo Pública podem associar-se com fins úteis, mas seus fins não podem ser oponíveis ao Estado, pelo que eles não poderiam se associar àquelas entidades cujos estatutos prevejam a greve. $\mathrm{O}$ argumento é de que contrariaria a eficácia do trabalho, a continuidade do serviço público - especialmente nos serviços de administração de justiça, de polícia (segurança, salubridade e moralidade). Reconhecem, pois, que a liberdade de agremiação é limitada pelo interesse do Estado, que se opōe sobre o interesse particular do funcionário.

Miguel Marienhoff (MARIENHOFF, s.d., p. 314), por sua vez, diz que há silêncio na legislação a respeito da possibilidade de os funcionários e empregados públicos se sindicalizarem, afirmando que a doutrina argentina a inadmite pelos seguintes motivos: porque sindicalização implicaria coação sobre a autoridade pública, que seria contrário ao regime jurídico dos servidores, e porque a atividade do sindicato poderia avançar sobre as funçōes do Estado. Por outro lado, o autor registra opiniōes no sentido de que se não devem proibir os sindicatos, mas regulamentá-los.

Manuel Diez (DIEZ, 1967, p. 480) entende que a Constituição consagra o direito de associação com fins úteis, mas não para constituir sindicatos. Percebe, entretanto, que, na prática, as associações têm caráter sindical e recorrem à greve, exatamente como os sindicatos do pessoal privado. Afirma que na doutrina argentina se reconhece o direito de associaçāo aos funcionários públicos, com limites ou com inteira liberdade, sendo perseguidas as finalidades de defesa da situação de seus cargos, ingresso, carreira e reformas para o melhor funcionamento do serviço público. Afirma também que, para negar ao funcionário o direito de sindicalização, argumenta-se que a finalidade é a greve, o que contraria o funcionamento contínuo do serviço, e que o sindicato é hostil à hierarquia administrativa. Por fim, também registra que na doutrina argentina se sustenta a regulamentação do sindicato, porque a greve não é a finalidade, mas um dos meios de ação do sindi- 
cato, e porque ainda que haja o caráter hostil deve-se regulá-lo de tal forma que os princípios de organização do Estado sejam respeitados.

A Corte Suprema argentina reconhece o direito de associação para os empregados públicos.

Geraldo Potobsky (POTOBSKY, 1997, p. 457) registra que a mudança de direcionamento da Corte Suprema argentina em matéria de tratados a partir de 1992 e a reforma constitucional de 1994 abriram novos rumos na dialética entre o direito internacional e sua projeção na ordem jurídica interna, com a primazia hierárquica do primeiro em relação às leis nacionais.

A Declaração Universal dos Direitos Humanos contempla o direito à liberdade de reunião e associação pacíficas, garantindo a toda pessoa o direito a organizar sindicatos e a neles ingressar para proteção de seus interesses. Um movimento sindical autenticamente livre e independente só pode se desenvolver numa situação em que estejam garantidos os direitos fundamentais da pessoa humana. A Argentina a incorporou em seu ordenamento jurídico.

Assim é que Potobsky (POTOBSKY, 1995, p. 15) entende que violaçōes às normas internacionais, incluídas as da Organização Internacional do Trabalho (OIT), são violações aos direitos humanos em geral.

As Convenções da OIT são tratados internacionais que, uma vez ratificados pelos Estados-membros, devem ser refletidos na legislação nacional.

No caso específico da Argentina, o artigo 75, item 22, da Constituição Nacional argentina, os tratados ratificados prevalecem sobre as leis.

Uma das quatro grandes áreas de estudo e regulamentação da OIT é a liberdade sindical e o direito à negociação coletiva.

A despeito da autoexecutoriedade dos Convênios da OIT, sem intervenção prévia, e de vários acordos da OIT assegurarem o direito do servidor público de associar-se em sindicatos e realizar negociaçōes coletivas, dentro das limitações que impõe o interesse público, muitos países signatários desses acordos não reconhecem esses direitos, não sendo esse o caso da Argentina.

Os dois Convênios da OIT regedores da matéria são o Convênio 87 sobre a liberdade sindical e a proteção do direito de sindicalização, de 1948, e o Convênio 98 sobre o direito de sindicalização e de negociação coletiva, de 1949, divergindo as opiniões quanto ao seu alcance.

O Convênio 87 da OIT sobre liberdade sindical e proteção do direito de sindicalização, ratificado pela Lei argentina $n^{\circ} 19.932 / 60$, expressa em seu artigo 2 que os trabalhadores e os empregadores, sem nenhuma distinção e sem autorização prévia, têm o direito de constituir as organizações que entenderem convenientes, assim como o de afiliar-se às mesmas, com a única condição de observar os estatutos dessas organizações. Em documento produzido em Brasília/DF, a OIT (OIT, 1993, p. 11) manifestou sua interpretação, que se aplica tanto ao setor público 
como ao privado e, consequentemente, também a servidores públicos. $\mathrm{O}$ artigo 9 prescreve que a legislação nacional deverá determinar até que ponto se aplicarão às forças armadas e à polícia as garantias previstas por este Convênio.

Por sua vez, o Convênio 98 da OIT, sobre o direito de sindicalização e de negociação coletiva, também ratificado pela Argentina, em 1956, em seus artigos 1 e 2, prevê que os trabalhadores e as organizações sindicais deverão gozar de adequada proteção contra todo ato de discriminação tendente a violar a liberdade sindical, que deve ser combatido. No artigo 5 , determina que a legislação nacional fixe sua aplicação às forças armadas e à polícia. No artigo 6 , diz que este Convênio não trata da situação dos funcionários públicos na administração do Estado, mas que não se deverá interpretar, de modo algum, em detrimento de seus direitos ou estatutos. Em documento produzido em Brasília/DF, a OIT (OIT, 1993, p. 7) manifestou sua interpretação, no sentido de que a exclusão de pessoas empregadas pelo Estado ou no setor público que não atuam como agentes da autoridade pública é contrária ao espírito da Convenção. Em seus consideranda, o Convênio 151 da OIT menciona que o Convênio 98 não é aplicável a certas categorias de empregados públicos. Estabelece a natureza voluntária da negociação coletiva e a obrigatoriedade de promoção dessa prática.

Há a Convenção 151 da OIT, chamada Convenção sobre as Relações de Trabalho na Administração Pública, ratificada pela Argentina pela Lei no $23.328 / 86$, que reconhece em seus consideranda que, devido à expansão dos serviços prestados pela administração pública em muitos países, devem existir sadias relações de trabalho entre as autoridades públicas e as organizaçōes de empregados públicos.

Mencionado Convênio aplica-se a todas as pessoas empregadas pela Administraçāo Pública (definindo, assim, seu conceito de empregado público), na medida em que não sejam aplicadas disposiçōes mais favoráveis de outros convênios internacionais de trabalho, conforme artigo $1^{\circ}$, competindo à legislação nacional determinar até que ponto se aplicam aos empregados de alto nível, com poder decisório, cargos diretivos ou cujas obrigaçōes sejam de natureza altamente confidencial, bem como às forças armadas e à polícia. Segundo a doutrina, não se fez distinção entre administração central, autárquica, descentralizada ou empresas públicas. Em documento produzido em Brasília/DF, a OIT (OIT, 1993, p. 7) entendeu que a presente Convenção trata do problema criado pela Convenção 98 , que excluiu os servidores públicos, empregados na administração do Estado.

O artigo 4 do Convênio 151 da OIT garante aos empregados públicos o direito de sindicalizaçāo, bem como às organizaçōes de empregados públicos, elencando o artigo 8, como meios de solução de conflitos, a negociação entre as partes.

Também foi feita no âmbito da OIT a Recomendação 159, de 1978, sobre as relações de trabalho na Administração Pública.

Para Hugo Mansueti (MANSUETI, 2000), um item significativo na liberdade sindical dos trabalhadores da Administração Pública se inicia com as Leis $\mathbf{n}^{\circ}$ 23.328/86 (OIT/151) e n⿳2 23.544/88 (OIT/154); assim, quando se sancionou a 
Lei $\mathrm{n}^{\circ} 23.551$, suas disposiçōes não distinguiram entre trabalhadores do setor público ou privado.

Cumpre, por fim, mencionar que, relativamente aos servidores vinculados à Administração Nacional, a UPCN (União do Pessoal Civil da Nação) é o grêmio majoritário, desde 1948, existindo ainda o grêmio das Forças Armadas (PECIFA), das Alfândegas, do serviço diplomático, dos funcionários da educação e dos da saúde. O pessoal militar e policial não se encontra sindicalizado, com movimentos destes últimos em favor da sindicalização. A UPCN teve uma participação importante no processo de reforma do Estado argentino do fim dos anos 80, como registram Bonifacio e Falivene (BONIFACIO; FALIVENE, 2002).

O direito de negociar coletivamente na Argentina tem duplo reconhecimento, como direito constitucional e como direito supranacional (SAN VICENTE, 1996, p. 115), tendo sido incorporado ao elenco dos direitos humanos fundamentais.

Para Jose Canasi (CANASI, 1981, p. 684), o denominador comum é a melhor forma de tutela dos interesses de ambas as partes. O diálogo atende tanto aos interesses dos servidores como da Administração Pública, com amplos benefícios para a coletividade, e as duas partes da relação trabalhista no setor público relativizam suas posiçōes na negociação.

Jorge Mancini (MANCINI, 1990, p. 134) entende que a fixação de remuneração via convenção coletiva é incompatível com os princípios da ciência financeira e orçamento público, e que como a negociação coletiva não é um direito absoluto, deve ser conciliado com outras normas constitucionais, tais como o princípio do orçamento público.

A Constituição argentina garante, em seu artigo 14 bis, o direito à negociação coletiva, como direito fundamental, assegurado aos grêmios ajustar convênios coletivos de trabalho.

Nos termos do Convênio 98 da OIT, o reconhecimento do direito de negociação coletiva somente se poderia excluir às Forças Armadas, à polícia e aos funcionários públicos na administração do Estado.

A possibilidade de negociar coletivamente com a Administração Pública, durante muito tempo debatida, achou uma solução no sentido positivo com os Convênios 151 e 154 da OIT, ambos aprovados pela Argentina, que já tem efetivado o sistema em algumas áreas da Administração Pública, como alfândega e empresas do Estado. Foram também editadas algumas Recomendaçōes, como a $\mathrm{n}^{\circ} \mathbf{9 1}$ sobre convênios coletivos, de 1951, a no 163 sobre a negociação coletiva, de 1981, e a no 159 sobre as relações de trabalho na Administração Pública, de 1978.

A despeito de haver várias normas sobre a possibilidade de negociação coletiva no setor público, há vozes isoladas na doutrina pela necessidade de uma lei nova integral, entendendo que há verdadeiro caos legislativo (SARDEGNA, 1995, p. 96), semelhante ao que ocorre no direito brasileiro... 
O governo argentino, ao ratificar o Convênio 154, na sua dupla condição de Estado-empregador e Estado-administrador, obrigou-se a fomentar a negociação coletiva voluntária a todas as categorias a que se aplica o Convênio, e determinou que a negociação coletiva não resultasse obstaculizada pela inexistência de regras que venham a reger seu desenvolvimento. Essa afirmativa vai perfeitamente ao encontro do defendido pelo Prof. Paulo Emílio Ribeiro de Vilhena, pois como sujeito de direitos deve se submeter às normas por ele editadas como Estado-ordem jurídica (VILHENA, 1965, p. 10).

A Convenção 154 da OIT, chamada Convênio sobre a negociação coletiva, ratificada pela Argentina pela Lei n 23.544/88, inclui expressamente a Administraçāo Pública, mas possibilita à legislação nacional que determine até que ponto as garantias previstas são aplicáveis às forças armadas e à polícia.

Compreende na expressão negociação coletiva todas as negociaçōes que têm lugar entre empregador e trabalhador, através de associações representantes, com o fim de fixar as condiçōes de trabalho ou regular as relaçōes entre empregadores e trabalhadores, nos termos de seu artigo $2^{\circ}$.

Também foi feita no âmbito da OIT a Recomendação 163, de 1981, sobre negociação coletiva.

O Brasil também ratificou os Convênios 98 e 154 da OIT.

A partir da Lei n² 24.185/92, segundo Hugo Roberto Mansueti (MANSUETI, 2000), habilitou-se a negociação coletiva para a Administração Pública nacional, processo que conclui com o convênio marco homologado pelo Decreto $n^{0}$ 66/99 e com a lei marco do emprego público ( $n^{\circ} 25.164$ ).

Segundo seu artigo 20, os preceitos desta lei serão interpretados em conformidade com o Convênio 154 da OIT, sendo aplicável às negociações coletivas que se celebrem entre a Administração Pública nacional e seus empregados, podendo as províncias e a municipalidade de Buenos Aires aderir ao sistema de negociação que aqui se estabelece.

$\mathrm{O}$ artigo $3^{\circ}$ da lei examinada exclui de sua aplicação o Presidente, o Vice-Presidente e o Procurador Geral da Nação; o Fiscal Geral de investigações administrativas e os fiscais adjuntos; os Ministros, Secretários e Subsecretários do Poder Executivo da Nação, o Procurador do Tesouro da Nação, funcionários superiores e assessores de gabinete; as pessoas que exerçam funçōes similares ou de hierarquia equivalente aos cargos mencionados; o pessoal militar e de segurança das forças armadas da Nação, Delegacia de Polícia nacional, Polícia Federal, serviço penitenciário federal ou organismos similares; o pessoal diplomático compreendido na lei de serviço exterior, que revistam hierarquia superior; o clero oficial; as autoridades e funcionários diretivos ou superiores de entes estatais ou organismos descentralizados nacionais; o pessoal que requeira regime particular pelas especiais características da atividade; e os já incorporados ao regime das convenções coletivas. Trata-se do que alguns doutrinadores argentinos chamam de funcionários públicos aqueles que têm competência para ordenar, classificação que refutamos, como já visto supra. 
Acertado o posicionamento da lei, pois os funcionários públicos eleitos mediante voto popular, aqueles detentores de cargos políticos, aqueles cuja atuação devido à natureza do cargo que desempenham - não se possa ver condicionada pela possibilidade de ter que discutir condições laborais, em especial salariais, aqueles que ocupam cargos de direção, hierarquia superior e segurança nacional realmente não podem ter suas condições discutidas pelas partes, por fazerem parte da estrutura do Estado, devendo suas posiçōes, até mesmo porque algumas são transitórias, ser reguladas de forma autônoma e mais rígida.

Quanto ao conteúdo material da negociaçāo, o artigo $8^{\circ}$ da lei em estudo prescreve que podem ser reguladas via negociação coletiva todas as questões trabalhistas que integram a relação de emprego, tanto as de conteúdo salarial como as demais condições de trabalho, exceto a estrutura orgânica da Administração Pública nacional, as faculdades de direção do Estado e o princípio de idoneidade como base do ingresso e promoção na carreira administrativa. No que tange às tratativas salariais ou àquelas referentes às condiçōes econômicas da prestação de trabalho, deverão se sujeitar ao legislado pela lei de orçamento e pelas pautas que determinaram sua elaboração.

O artigo 18 da lei determina que, no início das negociaçōes, as partes acordem mecanismos de autorregulação dos conflitos, tais como abstenção ou limitação de medidas de ação direta que possam afetar a prestação de serviços públicos essenciais, bem como os serviços mínimos cuja prestação deva ser garantida durante as medidas de ação direta, não excluindo, todavia, a aplicação das disposições legais que regem a espécie.

No que se refere à remuneração e criação de cargos, também não impedem a negociação coletiva, com possibilidade de se redigir proposta de lei nos termos acordados.

Não se pode olvidar que, para a plena produção de efeitos, dependerá da incorporação, em cada caso concreto, de atos dos Poderes Executivo ou Legislativo, de modo a harmonizar a negociação coletiva dos servidores públicos com a competência constitucional dos Poderes do Estado. Desse modo, restam observados os princípios da legalidade e, sobretudo, do Estado Democrático de Direito nas relaçōes entre a Administração e o seu pessoal.

Assim, no direito argentino, o empregado público, os trabalhadores estatais, podem ter sua atividade regulada via negociação coletiva, cujos termos do acerto devem ser compatíveis com o regime público.

\section{Considerações finais}

No direito brasileiro e no direito argentino, é faticamente possível e juridicamente se podem operacionalizar as garantias de sindicalização e negociação coletiva aos servidores públicos - de acordo com o conceito adotado para este último. 
Por outro lado, os argumentos contrários a essa sindicalizaçāo e negociação coletiva são frágeis, pois são meios pacíficos objetivando a melhor conciliação entre os interesses. Não se coaduna com a verdade o argumento de que o fim da sindicalização e da negociação coletiva é a greve, pois que um dos maiores benefícios que a negociação coletiva traz é a diminuição das greves. De outro lado, como forma de pressão durante as negociações, é legítima a greve como uma das estratégias do sindicato para superar a ruptura da negociação.

É urgente a necessidade, devido à situação fática mencionada, com prejuízos muito grandes à Administração Pública, aos servidores e à população, de regulamentação dos sindicatos e das formas de negociação coletiva no setor público, especialmente no Brasil, a fim de que se estabeleçam as futuras situaçōes que podem daí advir, com a possibilidade de deflagração de greve, devendo ser, pois, previamente estabelecidas as condiçōes de prestação dos serviços públicos, e em especial dos serviços mínimos, de tal forma que os princípios de organização do Estado sejam respeitados.

Como o Mercosul já tem conduzido as sociedades de seus Estados-Partes a avanços institucionais prodigiosos (FONTOURA, 2000, p. 56), não deverá ser diferente em matéria de regulamentação de institutos justrabalhistas, podendo, para a harmonia das relações no bloco, a legislação argentina, bem mais avançada no que tange ao direito coletivo do trabalho no setor público, como visto, servir de diretriz ao direito brasileiro.

Admitem-se, neste trabalho, as restrições quanto à aplicabilidade dos institutos de direito coletivo estudados àqueles funcionários públicos de alta hierarquia, imbuídos de poder decisório, detentores de cargos diretivos ou cujas obrigações sejam de natureza altamente confidencial, detentores de mandatos ou cargos políticos, bem como ao pessoal de segurança - como as forças armadas e a polícia, devido às especificidades da natureza de cada cargo e por fazerem parte da estrutura do Estado, devendo suas posições, até mesmo porque algumas são transitórias, serem reguladas de forma diferenciada.

O direito à liberdade sindical e o direito de negociar coletivamente são direitos humanos fundamentais, devendo, pois, serem reconhecidos pelos países que se dizem democráticos, como o Brasil e a Argentina.

Considerar que não é permitida a sindicalização e a negociação coletiva dos servidores públicos por falta de legislação é negar eficácia às Constituiçōes dos Estados, às normas da Organização Internacional do Trabalho, aos direitos humanos, e fechar os olhos para a realidade do serviço - servidor público.

Defendemos a sindicalização e a negociação coletiva dos servidores públicos, como forma de exercerem suas garantias fundamentais como trabalhadores que são, e de se evitarem medidas drásticas, como a greve. Uma das questões mais importantes é o resultado das negociaçōes, que poderá ser um protocolo de intenções, a seguir tramitação regular e o processo legislativo, ficando assegurada aos 
servidores públicos, caso o projeto não surtisse os efeitos acordados, a greve como meio legítimo de ação.

Como visto, a doutrina tradicional e a jurisprudência dos países estudados ainda não avançaram muito, já tendo a legislação nacional, especialmente a argentina, avançado nesse sentido. No que tange às normas da Organização Internacional do Trabalho, estão anos-luz à frente, nessa tendência universal de se assegurar proteção ao trabalho, e via de consequência à pessoa do trabalhador que, seja no setor privado ou no público, trata-se de trabalho humano, que deve, em qualquer e por todas as suas formas, ser tutelado.

\section{Referências}

ANASTÁSIA, Antônio Augusto Junho. Regime jurídico único do servidor público. Belo Horizonte: Del Rey, 1990.

ARGENTINA. Constitución de la Nación Argentina, de 22 de agosto de 1994. República Argentina - Ministerio de Economía y Producción. Disponível em: < http://infoleg. mecon.gov.ar/txtnorma/ConstitucionNacional.htm>. Acesso em: 4 mar. 2004.

. Ley $\mathrm{n}^{\mathrm{o}} 23.328$, de 8 de setembro de 1986. Aprueba el Convenio 151 de la OIT sobre protección de derechos de sindicacion y procedimientos para empleo en la Administración Pública. República Argentina - Ministerio de Economía y Producción. Disponível em: <http://infoleg.mecon.gov.ar/scriptsl/busquedas/ cnsnorma.asp? tipo $=$ Ley\&nro=23328 > . Acesso em: 20 mar. 2004.

Ley $\mathrm{n}^{\circ} 23.544$, de 15 de enero de 1988. Ratificación del Convenio 154 adoptado por la OIT. República Argentina - Ministerio de Economía y Producción. Disponivel em: <http://infoleg.mecon.gov.ar/scripts1/busquedas/cnsnorma. asp? tipo=Ley\&nro=23544>. Acesso em: 20 mar. 2004.

. Ley $\mathrm{n}^{\circ} 23.551$, de 14 de abril de 1988. Asociaciones sindicales - garantia de libertad. República Argentina - Ministerio de Economía y Producción. Disponível em: <http://infoleg.mecon.gov.ar/txtnorma/20993.htm>. Acesso em: 27 jun. 2004.

. Ley $\mathrm{n}^{\circ} 24.185$, de 11 de noviembre de 1992. Establécense las disposiciones por las negociaciones colectivas que se celebren entre la Admnistración Pública Nacional y sus empleados. República Argentina - Ministerio de Economía y Producción. Disponível em: <http://infoleg.mecon.gov.ar/txtnorma/583.htm>. Acesso em: 27 jun. 2004.

BIELSA, Rafael. Derecho administrativo. 6. ed. Buenos Aires: La Ley, 1964. t. 3.

BONIFACIO, José Alfredo; FALIVENE, Graciela. Análisis comparado de las relaciones laborales em la administración pública latinoamericana. CLAD, Argentina, 2002. Disponível em: <http://www.clad.org.ve/siare/innotend>. Acesso em: 4 maio 2004. 
BRASIL. Constituição federal: coletânea de legislação administrativa. Odete Medauar (Org.), obra coletiva de autoria da Editora Revista dos Tribunais, com a coordenação de Giselle de Melo Braga Tapai. 4. ed. rev., atual. São Paulo: Revista dos Tribunais, 2004.

. Lei $\mathrm{n}^{\circ}$ 9.527, de 10 de dezembro de 1997. Altera dispositivos das Leis $\mathrm{n}$ 오 8.112 , de 11 de dezembro de $1990,8.460$, de 17 de setembro de 1992, e 2.180, de 5 de fevereiro de 1954, e dá outras providências. Presidência da República. Disponível em: <http://www.planalto.gov.br/ccivil_03/Leis/L9527.htm>. Acesso em: 27 jun. 2004.

Supremo Tribunal Federal. Ação Direta de Inconstitucionalidade n 492-1 - DF, Brasília, DF, 12 de novembro de 1992. Lex: jurisprudência do STF, São Paulo, $n^{\circ} 175$, p. 49-90, jul. 1993.

CANASI, Jose. Derecho administrativo. Parte general. Buenos Aires: Depalma, 1981. v. 1.

CRETELLA JÚNIOR, José. Tratado de direito administrativo. Rio de Janeiro: Forense, 1966. v. 1.

DI PIETRO, Maria Sylvia Zanella. Direito administrativo. 10. ed. São Paulo: Atlas, 1999.

DIEZ, Manuel Maria. Derecho administrativo. Buenos Aires: Bibliografica Omeba, 1967. t. 3.

DROMI, Roberto. Reforma do Estado argentino. Revista de Direito Público, a. 25, nº 100, p. 109-137, out./dez. 1991.

FONTOURA, Jorge. O avanço constitucional argentino e o Brasil. Revista de Informação Legislativa, Brasília, a. 37, nº 146, p. 55-59, abr./jun. 2000.

JIMÉNEZ, Miguel. Éxito de la huelga general de 36 horas en Argentina: convocada otra de 48 horas para los días 1 y 2 de marzo. El Militante, no 136, jan./fev. 2001. Disponível em: <http://www.elmilitante.org/elmilt136/arg_136.htm>. Acesso em: 4 maio 2004.

LEITE, Carlos Henrique Bezerra. A greve do servidor público civil e os direitos humanos. Jus Navigandi, Teresina, a. 6, $\mathrm{n}^{\circ}$ 54, fev. 2002. Disponível em: <http:// wwwl.jus.com.br/doutrina/texto.asp?id=2612>. Acesso em: $1^{\circ}$ jun. 2004. Elaborado em dez. 2001.

LÓPEZ, Guillermo A. F. El modelo sindical argentino. Derecho del Trabajo, a. LV, no 10, 1995-B, p. 1765-1768, Oct. 1995.

MAIORANO, Jorge Luis. Armonizacion del derecho administrativo em el Mercosul. Revista dos Tribunais, $\mathrm{n}^{\circ}$ 699, p. 23-28, jan. 1994. 
MANCINI, Jorge Rodríguez. La negociación colectiva. Buenos Aires: Astrea, 1990. p. $133-147$.

. Revista de las posibilidades de la negociación colectiva en el derecho argentino actual. Derecho del Trabajo, a. LVIII, n³, 1998-A, p. 439-450, mar. 1998.

MANSUETI, Hugo Roberto. O direito do trabalho na sociedade argentina. In: ENCONTRO NACIONAL DE ESCOLAS DA MAGISTRATURA DO TRABALHO, 1. 2000, São Paulo. Disponível em: <http://www2.mansueti.com.ar/pdf/setiembre2000.pdf > . Acesso em: 12 maio 2004.

MARANHÃO, Délio; CARVALHO, Luiz Inácio Barbosa. Direito do trabalho. 17. ed. Rio de Janeiro: Fundação Getulio Vargas, 1993.

MARIENHOFF, Miguel S. Tratado de derecho administrativo. Buenos Aires: Abeledo Perrot, s.d. t. 3.

MEIRELLES, Hely Lopes. Direito administrativo brasileiro. 24. ed. Sāo Paulo: Malheiros, 1999.

MELLO, Celso Antônio Bandeira de. Curso de direito administrativo. 11. ed. São Paulo: Malheiros, 1999.

ORGANIZAÇÃO INTERNACIONAL DO TRABALHO. Princípios, normas e procedimentos da Organização Internacional do Trabalho referentes à liberdade sindical. Brasília: OIT, 1993.

. Convenio 87 sobre la libertad sindical y la protección del derecho de sindicación, 1948. Organización Internacional del Trabajo. Disponível em: <http://www. ilo.org/ilolex/cgi-lex/convds.pl?C087>. Acesso em: 20 mar. 2004.

Convenio 98 sobre el derecho de sindicación y de negociación colectiva, 1949. Organización Internacional del Trabajo. Disponível em: < http://www.ilo.org/ ilolex/cgi-lex/convds.pl?C098>. Acesso em: 20 mar. 2004.

. Convenio 151 sobre las relaciones de trabajo en la administración pública, 1978. Organización Internacional del Trabajo. Disponível em: <http://www.ilo.org/ ilolex/cgi-lex/convds.pl?C151>. Acesso em: 20 mar. 2004.

Convenio 154 sobre la negociación colectiva, 1981. Organización Internacional del Trabajo. Disponível em: <http://www.ilo.org/ilolex/cgi-lex/convds. pl?C154>. Acesso em: 20 mar. 2004.

POTOBSKY, Geraldo Von. La legislación argentina frente a las normas de la Organización Internacional del Trabajo. Derecho del Trabajo, a. LV, no 1, 1995-A, p. 15-27, jan. 1995.

Los convenios de la Organización Internacional del Trabajo: ¿una nueva dimensión en el orden jurídico interno? Derecho del Trabajo, a. LVII, nº 3, 1997-A. p. 457-473, mar. 1997 . 
RIVERO, Jean. Curso de direito administrativo comparado. Tradução de José Cretella Jr. São Paulo: Revista dos Tribunais, 1995. p. 156-157.

SAN VICENTE, Osvaldo Mantero de. Derecho del trabajo de los paises del Mercosur: un estudio de derecho comparado. Montevideo: Fundación de Cultura Universitaria, 1996.

SARDEGNA, Miguel. Las relaciones laborales en el Mercosur. Buenos Aires: La Rocca, 1995.

TAMAYO G., Eduardo. La región más peligrosa del mundo para sindicalistas. ALAI, set. 2000. Disponível em: <http://alainet.org/active/show_text.php3?key=931>. Acesso em: 4 maio 2004.

VILHENA, Paulo Emílio Ribeiro de. Contrato de trabalho com o Estado. 1965, 163 p. Tese (docência livre da cadeira de direito do trabalho) - Faculdade de Ciências Econômicas da Universidade de Minas Gerais.

. Direito do trabalho \& fundo de garantia. São Paulo: LTr, 1978. 